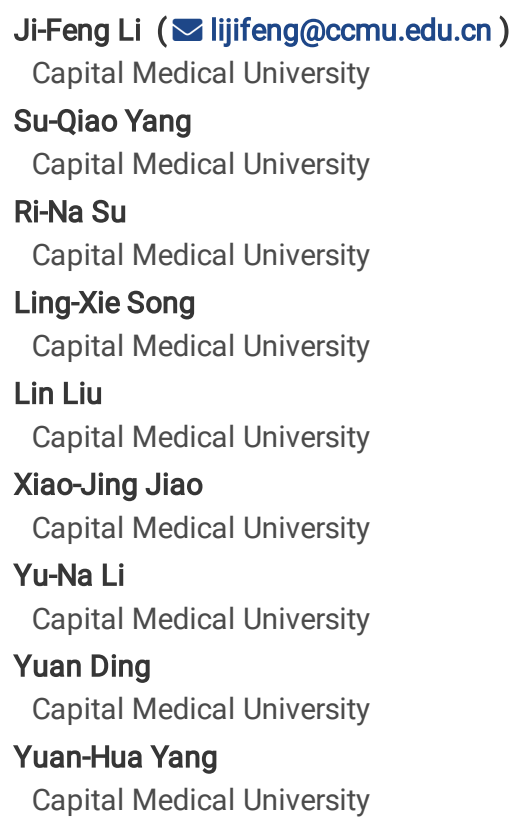

Ji-Feng Li ( $\sim$ lijifeng@ccmu.edu.cn )

Capital Medical University

Su-Qiao Yang

Capital Medical University

Ri-Na Su

Capital Medical University

Ling-Xie Song

Capital Medical University

Lin Liu

Capital Medical University

Xiao-Jing Jiao

Capital Medical University

Yu-Na Li

Capital Medical University

Yuan Ding

Capital Medical University

Yuan-Hua Yang

Capital Medical University

\title{
Concomitant Cancer Related Venous Thromboembolism and Arterial Thromboembolism
}

\section{Research Article}

Keywords: Venous thromboembolism, Arterial thromboembolism, Cancer, Trousseau syndrome

Posted Date: February 17th, 2022

DOI: https://doi.org/10.21203/rs.3.rs-1313025/v1

License: @ (1) This work is licensed under a Creative Commons Attribution 4.0 International License. Read Full License 


\section{Abstract}

Background: Thrombosis is closely related with cancer patients. Venous thromboembolism such as pulmonary thromboembolism and deep vein thrombosis are more frequently occurred in cancer patients. Arterial thromboembolism such as myocardial infarction and ischemic stroke were less occurred. Venous thromboembolism and arterial thromboembolism were rarely concomitantly occurred in cancer patients, especially ahead of cancer diagnosis.

Methods: Five patients who suffered from venous thromboembolism and arterial thromboembolism sequentially and then cancer was diagnosed were enrolled and followed up until the patient died or until June 2021. The medical records were retrospectively reviewed to evaluate the clinical characteristics, image findings and the outcomes.

Results: Three women and two men were renrolled, with a mean age of 63.2 years (range, 47-76 years). Four patients suffered from ischemic stroke, and the lesions showed by magnetic resonance manifested bilateral diffuse changes. One patient suffered from lower limb arterial thromboembolism. Four patients suffered from pulmonary thromboembolism diagnosed by CTPA or ultrasound (among them, two patients with deep venous thrombosis simultaneously), one patient suffered from solely deep venous thrombosis. Pulmonary adenocarcinoma was diagnosed in two patients, and one skin basal cell carcinoma, one ovarian clear cell adenocarcinoma and one rectal adenocarcinoma were diagnosed in the other three patients. Four patients received cancer related treatment and all patients received anticoagulation therapy. Except the patient without cancer related treatment who survived for 3 months, all the other four patients survived more than 2 years.

Conclusion: Cancer can present as venous thromboembolism or arterial thromboembolism or both in advance. Cancer should be screened in patients with venous thromboembolism, especially those with concomitant arterial thromboembolism.

\section{Introduction}

The association between cancer and thrombosis has been elucidated as known as Trousseau syndrome sometimes[1] . About 20\%-30\% of venous thromboembolism (VTE) are associated with cancer[2]. The arterial thromboembolism (ATE) occurred in about 0.2-9.1\% cancer patients[3, 4]. But VTE and ATE occurred concomitantly in the same cancer patients were rare, especially before the diagnosis of cancer. Here we reported a series of cancer patients with VTE and ATE sequentially developed ahead of cancer.

\section{Materials And Methods}

This study is in accordance with the amended declaration of Helsinki. Obtained informed consents have been obtained from patients for their medical data to be used in the study.

We reviewed five patients admitted for VTE or ATE, and cancer was diagnosed during the process. ATE or VTE occurred sequentially. Histopathological examination in all cases confirmed the diagnosis of cancer. VTE or ATE was diagnosed by images, as pulmonary thromboembolism (PTE) was diagnosed by CT pulmonary angiography (CTPA), DVT was diagnosed by ultrasound of lower extremity veins. Myocardial infarction (MI) was diagnosed by symptoms, electrocardiogram and serum markers of myocardial injury. Ischemic stroke (IS) was diagnosed by brain CT or magnetic resonance (MR), lower limb arterial thromboembolism was diagnosed by vascular angiography. All the patients were followed up to June 2021.

\section{Results}

The demographic and clinical features of the five patients are listed in Table 1. There are three women and two men, with a mean age of 63.2 years (range, 47-76 years). None of the five patients had a history of hypertension or diabetes. Two patients were admitted for IS and VTE was diagnosed 2 days and 5 days thereafter. Three patients were admitted for PTE and arterial ischemic events were diagnosed concomitantly and 5 days and 20 days respectively.

The images of the ATE and VTE of the 5 patients were showed in Figure 1. Four patients suffered from IS, and the lesions showed by MR manifested diffuse changes involved in both sides of brain. One patient suffered from lower limb ATE. The images of VTE showed that 4 patients suffered from PTE (among them, 2 patients with DVT simultaneously), 1 patient suffered from solely DVT.

The pathological images of cancer were showed in Figure 2. Pulmonary adenocarcinoma was diagnosed in 2 patients, and 1 skin basal cell carcinoma, 1 ovarian clear cell adenocarcinoma and 1 rectal adenocarcinoma were diagnosed in the other 3 patients.

All the 5 patients were followed up by telephone call or direct consultation until June 2020. The treatment of cancer was different in different patients, 2 patients received operation, 1 patient received traditional chemotherapy, 1 patient received gene targeted chemotherapy, 1 patient received no cancer targeted therapy. All the patient received anticoagulation regularly mainly by low molecular weight heparin (LMWH). Four of the 5 patients in our cohort received LMWH and one received rivaroxaban after the first 3 months anticoagulantion therapy with LMWH. The 2 patients who received operation were treated with $\mathrm{LMWH}$ for 3 months and then were monitored mainly by D-dimer. The patients who received traditional 
chemotherapy and the patient who received no cancer targeted therapy were treated with LMWH continuously. The patient who received gene targeted chemotherapy was treated with LMWH and rivaroxaban continuously. But not all the patient received antiplatelet therapy like aspirin, some was treated temporarily, some received no according therapy. Except the patient without cancer related treatment who survived for 3 months, all the other four patients survived more than 1.5 years.

\section{Discussion}

The association between cancer and thrombosis was first described in 1823[5]. Cancer-associated thrombosis (CAT) is also known as Trousseau syndrome, especially in patients with VTE[6]. Development of VTE in patients with cancer is associated with a poorer prognosis[7, 8]. Now, most guidelines in different fields all suggested for screening of occult cancers in patients with venous thromboembolism[9, 10]. However, arterial thrombosis in cancer patients has received much less attention[11]. Recently, ATE in cancer patients has been gradually recognized[3, 4]. The ATE in cancer patients mainly includes non-fatal MI, IS and peripheral arterial events. ATE increased risk of mortality in cancer patients[3, 7]. Here we summarized the basic clinical characteristics, image characteristics and prognosis of 5 patients with both VTE and ATE in cancer patients.

Many kinds of cancer can develop VTE. Current estimates are that 20\%-30\% of VTEs are associated with cancer[2]. Several tumor sites, including lung, brain, pancreas, stomach, ovary and kidney have the strongest reported association with VTE[12, 13]. Many kinds of cancer can develop ATE. Incidence of $0.27 \%-9.1 \%$ of ATEs has been reported in cancer patients[7, 14]. Lung, prostate, colorectal, bladder, pancreatic, gastric cancers have been reported associated with ATE[14]. In our cohort, all the patients received the routine screening of etiology of VTE and ATE. The common cause of VTE and ATE were excluded. Among the 5 patients, 2 patients were diagnosed as lung cancer. It is similar to the previous reports that more patients with lung cancer suffered from ATE[7, 15]. Ovarian and rectal cancers have also been reported before. However, one patient was diagnosed as skin cancer. It has not been reported before.

It seems that the VTE in cancer patients has no specific imaging characteristics in CTPA, angiography or ultrasound detection. The main characteristic of cancer related VTE is that most PTE was not high-risk[16-18]. However, the imaging of cancer related ATE has some unique characteristics. Bilateral cerebral embolism has been reported as a characteristic feature of patients with Trousseau syndrome[19]. Non-fatal MI was mostly reported in cancer related ATE[3]. In our cohort, in the 4 patients with IS, 3 were bilateral lesions, which was similar with previous reports. And the patient developed MI is also not-fatal. This patient developed IS and MI after the episode of PTE and diagnosis of lung adenocarcinoma. Though the patient received no therapy for the cancer, he still survived for 1.5 years with anticoagulation therapy and supporting therapy.

The main therapy of Trousseau syndrome is the therapy of cancer. In our cohort, two patients received operation, 1 patient received traditional chemotherapy, 1 patient received gene targeted chemotherapy and 1 patient received no cancer targeted therapy. Anticoagulation is another important therapy for cancer-related thrombosis and LMWH has been the preferred agent in the last decade[9, 20]. Recently, direct oral anticoagulants (DOAC), mainly rivaroxaban, edoxaban and apixaban have been proved effective in treating CAT[21-23]. Four of the five patients in our cohort received LMWH and 1 received rivaroxaban. All the patients have no recurrent venous thrombosis and no major bleeding was reported. The treatment of cancer related ATE is controversial and challenging[24]. In our cohort, no patients received long-term anti-platelet therapy.

\section{Conclusion}

Our data suggest that VTE and ATE can occurred in the same cancer patient. Bilateral cerebral embolism seems to be a characteristic feature of patients with ATE. MI was non-fatal and PTE is not high-risk. The treatment mainly includes cancer targeted therapy and anticoagulation. LMWH and DOAC can be used in CAT.

\section{Declarations}

\section{Ethics approval and consent to participate}

The Ethics Committee of Beijing Chao-Yang Hospital of Capital Medical University approved the protocol and a written informed consent was obtained from all the patients.

This study is in accordance with the amended declaration of Helsinki. Obtained informed consents have been obtained from patients for their medical data to be used in the study.

\section{Consent for publication}

All of the authors listed have contributed to the manuscript and approved its final, submitted form, and that the authors have read and agree to your Editorial Policies.

Informed consent was obtained from all subjects and/or their legal guardian(s) for publication of identifying information/images in an online openaccess publication. 


\section{Availability of data and materials}

The datasets generated and/or analysed during the current study are not publicly available due to the policy of the hospital, but are available from the corresponding author on reasonable request.

\section{Competing interests}

The authors have declared that no competing interest exists.

\section{Funding}

This work was partly supported by the fund of National Natural Science Foundation of China (31670928). The funder had no role in study design, data collection and analysis, decision to publish, or preparation of the manuscript.

No part of the research presented has been funded by tobacco industry sources or other organization.

\section{Authors' contributions}

Ji-Feng Li, Su-Qiao Yang, Ri-Na Su enrolled patients. Ling-Xie Song recheck the pathology of the specimen. Lin Liu, Xiao-Jing Jiao, Yu-Na Li, Yuan Ding followed the patients. Ji-Feng Li and Yuan-Hua Yang complete the manuscript.

\section{Acknowledgements}

N/A

\section{References}

1. Key NS: New players in Trousseau syndrome. Blood 2015, 126(11):1270-1272.

2. Timp JF, Braekkan SK, Versteeg HH, Cannegieter SC: Epidemiology of cancer-associated venous thrombosis. Blood 2013, 122(10):1712-1723.

3. Grilz E, Konigsbrugge O, Posch F, Schmidinger M, Pirker R, Lang IM, Pabinger I, Ay C: Frequency, risk factors, and impact on mortality of arterial thromboembolism in patients with cancer. Haematologica 2018, 103(9):1549-1556.

4. De Stefano V: Arterial thrombosis and cancer: the neglected side of the coin of Trousseau syndrome. Haematologica 2018, $103(9): 1419-1421$.

5. Stein PD, Beemath A, Meyers FA, Skaf E, Sanchez J, Olson RE: Incidence of venous thromboembolism in patients hospitalized with cancer. The American journal of medicine 2006, 119(1):60-68.

6. Carrier M, Le Gal G, Wells PS, Fergusson D, Ramsay T, Rodger MA: Systematic review: the Trousseau syndrome revisited: should we screen extensively for cancer in patients with venous thromboembolism? Ann Intern Med 2008, 149(5):323-333.

7. Brenner B, Bikdeli B, Tzoran I, Madridano O, Lopez-Reyes R, Surinach JM, Blanco-Molina A, Tufano A, Nunez JJL, Trujillo-Santos J et al: Arterial Ischemic Events Are a Major Complication in Cancer Patients with Venous Thromboembolism. The American journal of medicine 2018, 131(9):1095-1103.

8. Papakotoulas P, Tsoukalas N, Christopoulou A, Ardavanis A, Koumakis G, Papandreou C, Papatsimpas G, Papakostas P, Samelis G, Andreadis C et al: Management of Cancer-associated Thrombosis (CAT): Symptomatic or Incidental. Anticancer Res 2020, 40(1):305-313.

9. Konstantinides SV, Meyer G, Becattini C, Bueno H, Geersing GJ, Harjola VP, Huisman MV, Humbert M, Jennings CS, Jimenez D et al: 2019 ESC Guidelines for the diagnosis and management of acute pulmonary embolism developed in collaboration with the European Respiratory Society (ERS): The Task Force for the diagnosis and management of acute pulmonary embolism of the European Society of Cardiology (ESC). Eur Respir J 2019, 54(3).

10. Howard LS, Hughes RJ: NICE guideline: management of venous thromboembolic diseases and role of thrombophilia testing. Thorax 2013, 68(4):391-393

11. Di Nisio M, Ferrante N, Feragalli B, De Tursi M, lacobelli S, Cuccurullo F, Porreca E: Arterial thrombosis in ambulatory cancer patients treated with chemotherapy. Thrombosis research 2011, 127(4):382-383.

12. Khorana AA, Connolly GC: Assessing risk of venous thromboembolism in the patient with cancer. J Clin Onco/2009, $27(29): 4839-4847$.

13. Khorana AA, Dalal M, Lin J, Connolly GC: Incidence and predictors of venous thromboembolism (VTE) among ambulatory high-risk cancer patients undergoing chemotherapy in the United States. Cancer 2013, 119(3):648-655.

14. Navi BB, Reiner AS, Kamel H, ladecola C, Okin PM, Elkind MSV, Panageas KS, DeAngelis LM: Risk of Arterial Thromboembolism in Patients With Cancer. J Am Coll Cardiol 2017, 70(8):926-938. 
15. Sanon S, Lenihan DJ, Mouhayar E: Peripheral arterial ischemic events in cancer patients. Vasc Med 2011, 16(2):119-130.

16. Moik F, Ay C: How I Manage Cancer-Associated Thrombosis. Hamostaseologie 2020, 40(1):38-46.

17. Moik F, Pabinger I, Ay C: How I treat cancer-associated thrombosis. ESMO Open 2020, 5(1).

18. Muster V, Gary T: Incidence, Therapy, and Bleeding Risk-Cancer-Associated Thrombosis in Patients with Glioblastoma. Cancers 2020, 12(6).

19. Umemura T, Yamamoto J, Akiba D, Nishizawa S: Bilateral cerebral embolism as a characteristic feature of patients with Trousseau syndrome. Journal of clinical neuroscience : official journal of the Neurosurgical Society of Australasia 2017, 42:155-159.

20. O'Connell C, Escalante CP, Goldhaber SZ, McBane R, Connors JM, Raskob GE: Treatment of Cancer-Associated Venous Thromboembolism with Low-Molecular-Weight Heparin or Direct Oral Anticoagulants: Patient Selection, Controversies, and Caveats. Oncologist 2021, 26(1):e8-e16.

21. Raskob GE, van Es N, Verhamme P, Carrier M, Di Nisio M, Garcia D, Grosso MA, Kakkar AK, Kovacs MJ, Mercuri MF et al: Edoxaban for the Treatment of Cancer-Associated Venous Thromboembolism. N Engl J Med 2018, 378(7):615-624.

22. Young AM, Marshall A, Thirlwall J, Chapman O, Lokare A, Hill C, Hale D, Dunn JA, Lyman GH, Hutchinson C et al: Comparison of an Oral Factor Xa Inhibitor With Low Molecular Weight Heparin in Patients With Cancer With Venous Thromboembolism: Results of a Randomized Trial (SELECT-D). J Clin Oncol 2018, 36(20):2017-2023.

23. McBane RD, 2nd, Wysokinski WE, Le-Rademacher JG, Zemla T, Ashrani A, Tafur A, Perepu U, Anderson D, Gundabolu K, Kuzma C et al: Apixaban and dalteparin in active malignancy-associated venous thromboembolism: The ADAM VTE trial. J Thromb Haemost 2020, 18(2):411-421.

24. Candeloro M, Guman NAM, Kraaijpoel N, Di Nisio M: Risk Assessment Models for Thrombosis and Anticoagulant-Related Bleeding in Ambulatory Cancer Patients. Semin Thromb Hemost 2021, 47(8):972-981.

\section{Tables}

Table 1. Demographic and clinical features of the patients in this study

\begin{tabular}{|c|c|c|c|c|c|c|c|c|c|c|}
\hline NO. & Sex & $\begin{array}{l}\text { Age } \\
\text { (Years) }\end{array}$ & Cancer & $\begin{array}{l}\text { Initial } \\
\text { disease }\end{array}$ & $\begin{array}{l}\text { Sequential } \\
\text { disease }\end{array}$ & $\begin{array}{l}\text { Time } \\
\text { course } \\
\text { between } \\
\text { ATE and } \\
\text { VTE }\end{array}$ & Metastasis & $\begin{array}{l}\text { Stage of } \\
\text { cancer (TNM) }\end{array}$ & $\begin{array}{l}\text { Cancer } \\
\text { treatment }\end{array}$ & Outcome \\
\hline 1 & Female & 76 & $\begin{array}{l}\text { skin basal cell } \\
\text { carcinoma }\end{array}$ & IS & PTE & 2 days & NO & T1 & Operation & $\begin{array}{l}\text { Survived } \\
\text { for more } \\
\text { than } 3.5 \\
\text { years }\end{array}$ \\
\hline 2 & Female & 47 & $\begin{array}{l}\text { ovarian clear cell } \\
\text { adenocarcinoma }\end{array}$ & IS & DVT & 5 days & YES & III & Chemotherapy & $\begin{array}{l}\text { Survived } \\
\text { for more } \\
\text { than } 2.5 \\
\text { years }\end{array}$ \\
\hline 3 & Female & 59 & $\begin{array}{l}\text { pulmonary } \\
\text { adenocarcinoma }\end{array}$ & $\begin{array}{l}\text { DVT } \\
\text { and } \\
\text { PTE }\end{array}$ & IS & 20 days & YES & IIIb (T1N3M0) & $\begin{array}{l}\text { Gene targeted } \\
\text { chemotherapy }\end{array}$ & $\begin{array}{l}\text { Survived } \\
\text { for more } \\
\text { than } 2.0 \\
\text { years }\end{array}$ \\
\hline 4 & Male & 72 & $\begin{array}{l}\text { pulmonary } \\
\text { adenocarcinoma }\end{array}$ & PTE & $\begin{array}{l}\text { IS and } \\
\text { AMI }\end{array}$ & $\begin{array}{l}5 \text { days } \\
\text { and } \\
11 \text { days }\end{array}$ & YES & IV (T4N3M1) & Untreated & $\begin{array}{l}3 \\
\text { months }\end{array}$ \\
\hline 5 & Male & 62 & $\begin{array}{l}\text { rectal } \\
\text { adenocarcinoma }\end{array}$ & $\begin{array}{l}\text { DVT } \\
\text { and } \\
\text { PTE }\end{array}$ & $\begin{array}{l}\text { Lower } \\
\text { limb ATE }\end{array}$ & 0 days & NO & $\begin{array}{l}\text { I } \\
\text { (T1NOM0) }\end{array}$ & Operation & $\begin{array}{l}\text { Survived } \\
\text { for more } \\
\text { than } 2.0 \\
\text { years }\end{array}$ \\
\hline
\end{tabular}

IS, Ischemic stroke; AMI, acute myocardial infarction; PTE, Pulmonary thromboembolism; DVT, Deep venous thrombosis; ATE arterial thromboembolism.

\section{Figures}



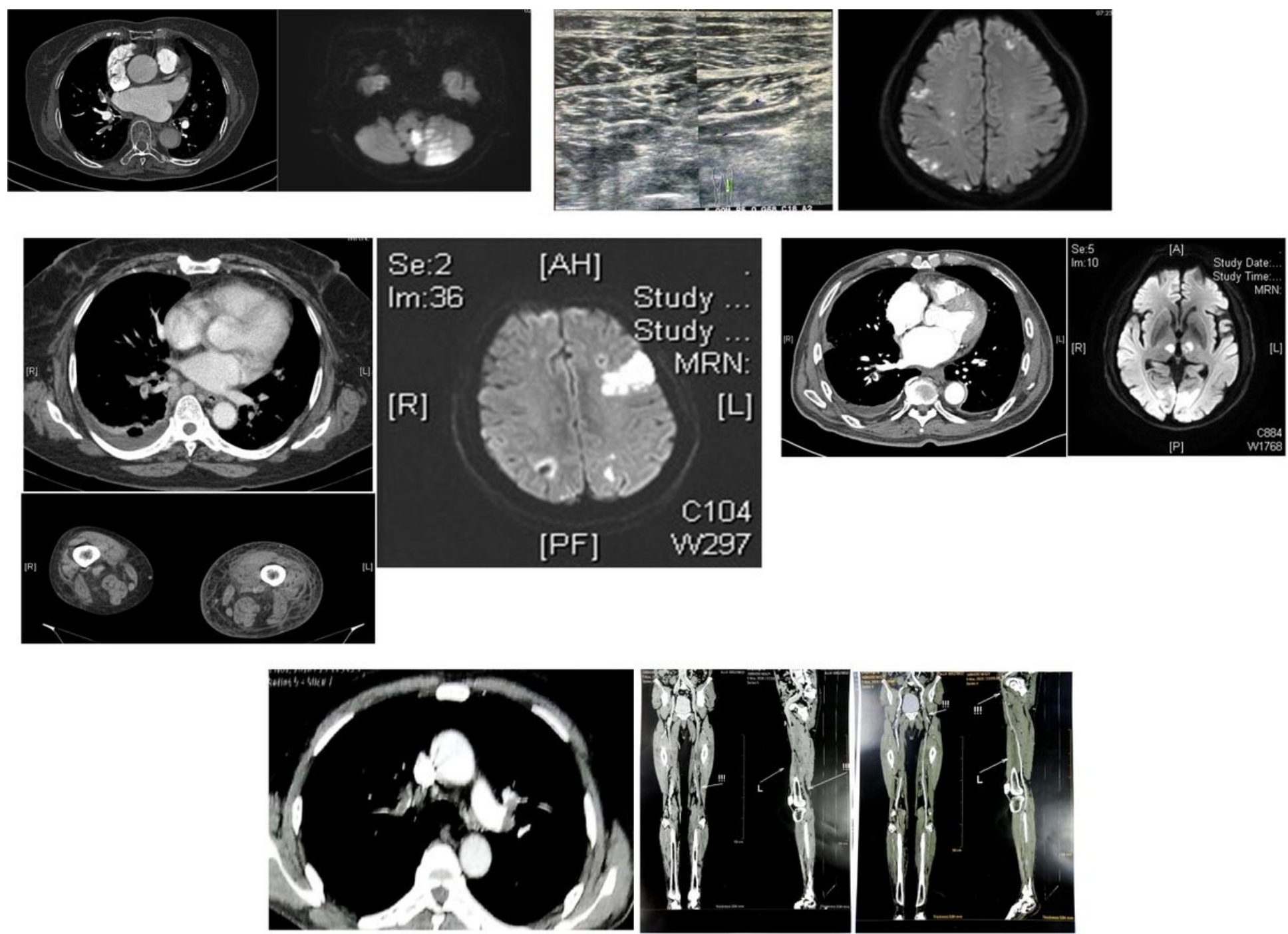

\section{Figure 1}

Imaging of VTE and ATE in the five cancer patients (1-5 represents the number of patients).
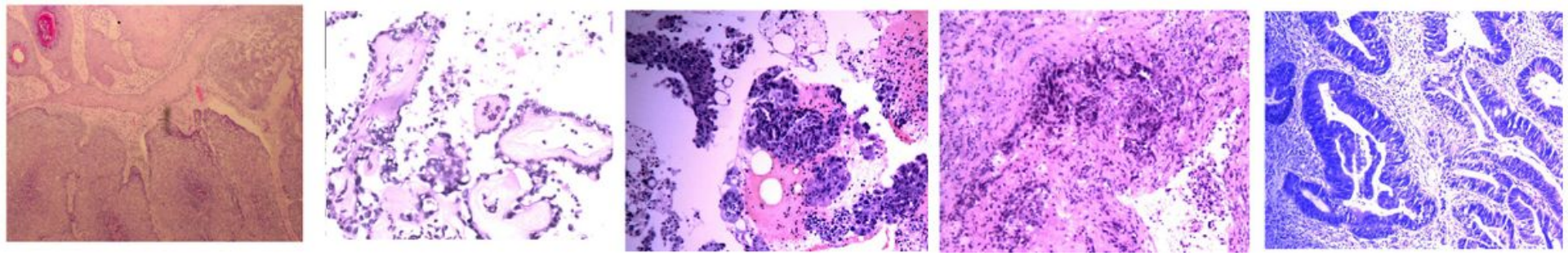

Figure 2

Pathological imaging of the five cancer patients (1-5 represents the number of patients). 